\title{
Tarzan: A Remote Tool Deployment System For the West Valley Development Project
}

Final Report

Reporting Date: 5/27/98 through 9/30/99

Principal Authors:

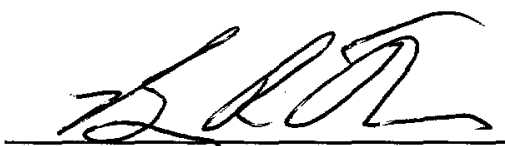

Bruce R. Thompson

Chief Technical Officer

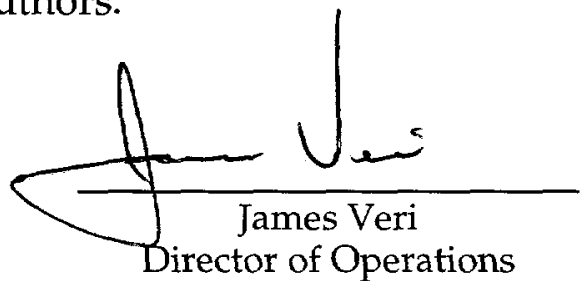

Report Date: September, 1999

DOE Award \#: DE-AR26-98-FT40410

Prepared by:

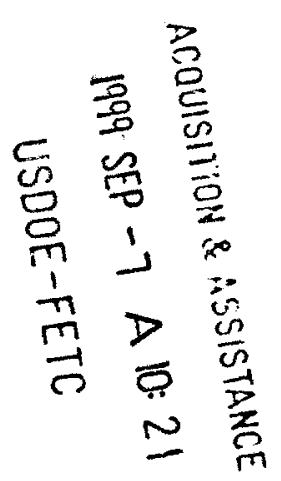

\section{RedZone Robotics}

2425 Liberty Avenue

Pittsburgh, PA 15222-4639

412-765-3064 


\section{DISCLAIMER}

Portions of this document may be illegible in electronic image products. Images are produced from the best available original document. 


\section{Disclaimer}

This report was prepared as an account of work sponsored by an agency of the United States Government. Neither the United Stated Government nor any agency thereof, nor any of their employees, makes any warranty, express or implied, or assumes any legal liability or responsibility for the accuracy, completeness, or usefulness of any information, apparatus, product, or process disclosed, or represents that its use would not infringe privately owned rights. Reference herein to any specific commercial product, process, or service by trade name, trademark, manufacturer, or otherwise does not necessarily constitute or imply its endorsement, recommendation, or favoring by the United Stated Government or any agency thereof. The views and opinions of authors expressed herein do not necessarily reflect those of the United States Government or any agency thereof. 


\section{Abstract}

RedZone Robotics, Inc. undertook a development project to build Tarzan, a Remote Tool Delivery system to work inside nuclear waste storage tanks $8 \mathrm{D}-1$ and $8 \mathrm{D}-2$ at the West Valley Demonstration Project (WVDP).

The removal of waste deposits from large storage tanks poses significant challenges during tank operations and closure. Limited access, the presence of chemical, radiological, and/or explosive hazards, and the need to deliver retrieval equipment to all regions of the tank exceed the capabilities of most conventional methods and equipment. Remotely operated devices for mobilizing and retrieving waste materials are needed. Some recent developments have been made in this area. However, none of these developments completely and cost-effectively address tanks that are congested with internal structures (e.g., support columns, cooling coils, fixed piping, etc.).

The Tarzan system consists of the following parts:

- Locomotor which is deployed in the tank for inspection and cleanup.

- Hydraulic power unit providing system power for the locomotor and deployment unit.

- Control system providing the man machine interface to control, coordinate and monitor the system.

This document presents the final report on the Tarzan project. 


\section{Table of Contents}

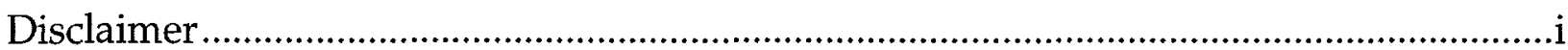

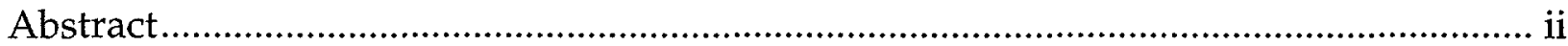

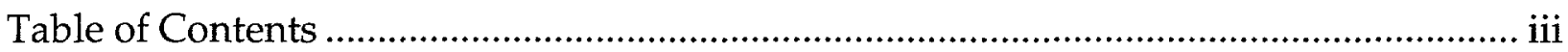

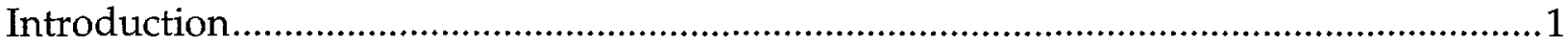

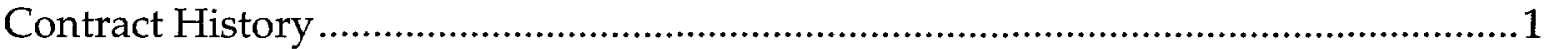

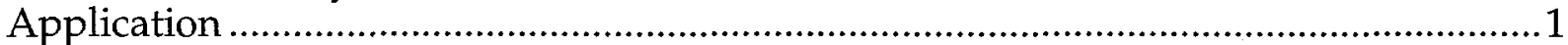

The West Valley Tanks ........................................................................... 1

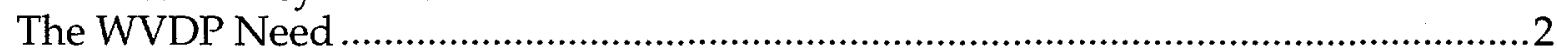

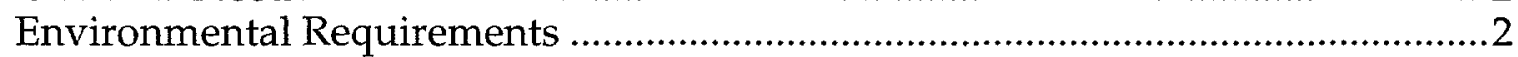

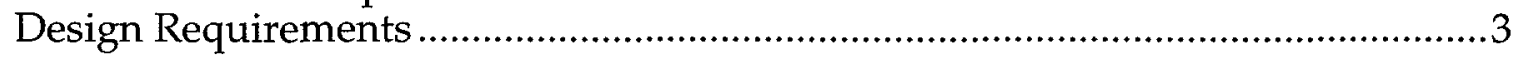

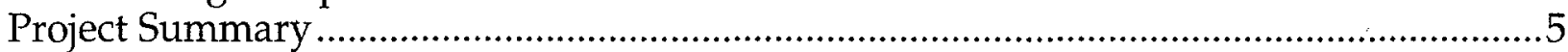

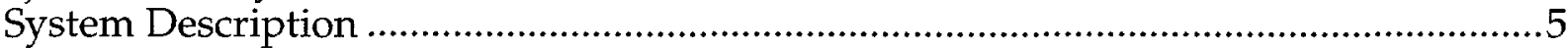

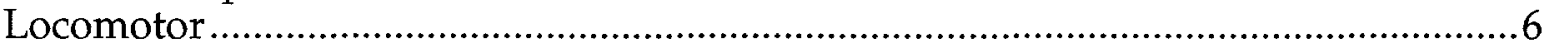

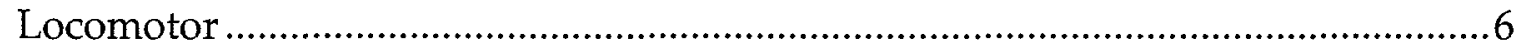

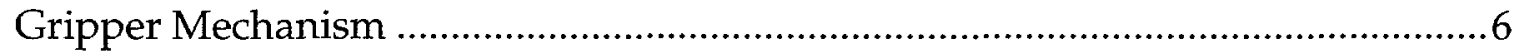

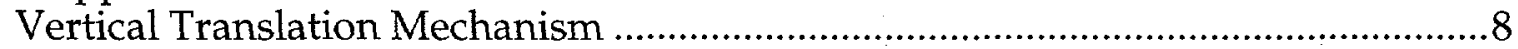

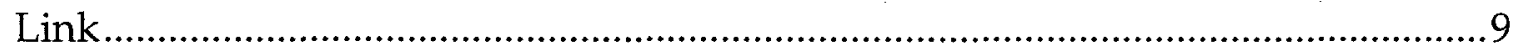

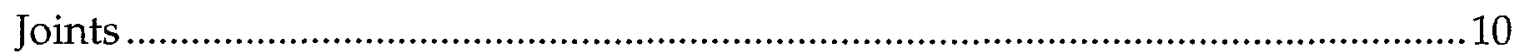

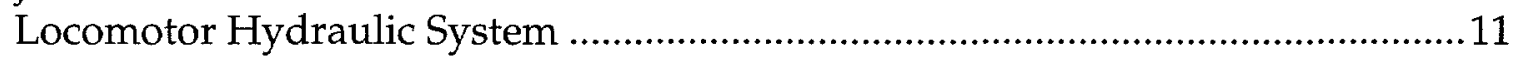

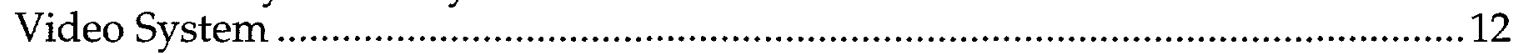

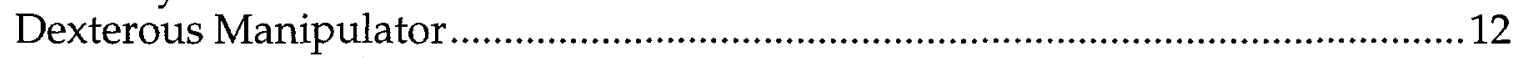

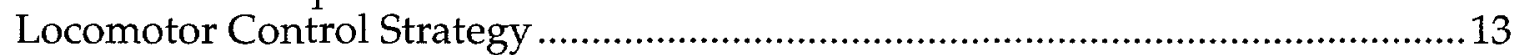

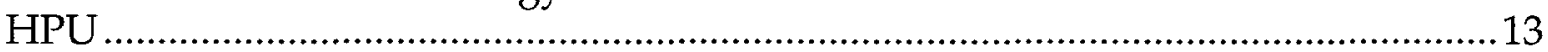

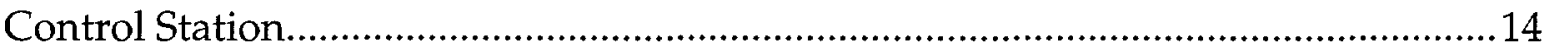

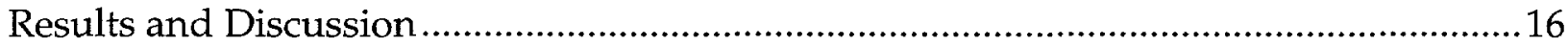

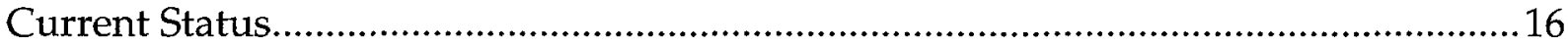

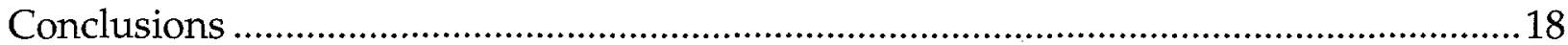

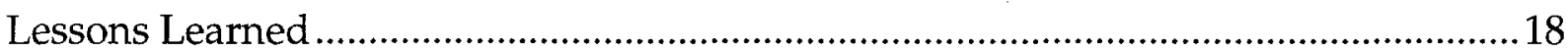




\section{Introduction}

The Tarzan project was initiated on April 11, 1997 with West Valley Nuclear Services (WVNS). The intention of the project is to build a robotic system capable of providing access to two high level waste tanks located on the West Valley site. The West Valley Demonstration Project (WVDP) has begun vitrifying the waste from these tanks and has been using large mixing pumps to sluice the remaining contents of the tanks, but due to significant structures located within the tanks, there was some question as to the success of such a method. As such, the Tarzan system was conceived to provide a tool giving access to the entire tank interior for final cleaning and closure activities.

\section{Contract History}

RedZone originally proposed this work through the DOE's Research Opportunity Announcement (ROA) program at the Federal Energy Technology Center (FETC), but due to time constraints the project was initiated directly through WVNS to accelerate the delivery. The initial Phases of Feasibility Study, Conceptual Design and a portion of the Detailed Design took place under this contract. In 1998 FETC notified RedZone that the project had been selected for award and in May of 1988 the project was transferred from WVNS to FETC. Additional technical and project support was provided by the DOE Office of Science and Technology, Tank Focus Area Program and Robotics Technology Development Crosscutting Program. Table 1 details the contract history by date.

\begin{tabular}{|c|c|l|l|}
\hline Start & End & Description & Contract \\
\hline $4 / 11 / 97$ & $3 / 27 / 98$ & $\begin{array}{l}\text { WVNS Feasibility/ } \\
\text { Conceptual Design }\end{array}$ & WVNS PO 19-89487-C-EK \\
\hline $3 / 28 / 98$ & $5 / 26 / 98$ & $\begin{array}{l}\text { WVNS Final Design/ } \\
\text { Fabrication/ Assembly }\end{array}$ & WVNS PO 19-89487-C-EK \\
\hline $5 / 26 / 98$ & Present & FETC Fabrication/Assembly & Contract DE-AR26-98-FT40410 \\
\hline
\end{tabular}

Table 1 Timetable

\section{Application}

\section{The West Valley Tanks}

The West Valley site is located in western New York State and has two underground waste storage tanks of 750,000 gallon capacity each. The tanks are of identical 


\section{RedZone}

construction, carbon steel, 70 feet in diameter, 27 feet high with extensive internal structure to support the tank roof. The internal structure consists of 8 inch diameter pipe columns on 10 foot centers running between the tank roof and an extensive grid of Wide Flange (WF) beams, cross bars, and standoffs that distribute the column load into the tank floor. One tank contains radioactive liquid and granular cesium loaded zeolite. The other tank contains accumulated radioactive waste including liquid, sludge, and zeolite. The load distribution structure near the floor of the tank makes it difficult to completely remove solids from the lower region of the tank by bulk agitation and pumping.

\section{The WVDP Need}

The pivotal issue in the waste retrieval and cleanup of the WVDP tanks is the ability to access all areas of the tank floor and internals while operating in a highly congested confined environment. A remote worksystem should position and enable use of a variety of tooling or end-effectors throughout the tank, including inspection cameras, waste removal equipment, and auxiliary equipment. The worksystem should perform two primary tasks: first, deliver and position sluicing water to wash down tank internals, and second, position waste removal equipment to move wastes to a separate in-tank pumping station. In addition, the system may be used for sampling or inspection operations within the tank, so full coverage of the tank internals is desired. To enhance effective use of removal and cleanup tooling, it was desired to develop a delivery system capable of transporting equipment weighing 100 to $200 \mathrm{lbm}$ throughout the tank, and resisting forces generated during operation (e.g. spray reaction). Additional requirements include the ability to deploy the worksystem through a single riser and allow relocation to another riser, and be retrievable when operational and in the event of equipment failure.

\section{Environmental Requirements}

1. Geometry of Tank Internal Structure: During construction of tank $8 \mathrm{D}-1$, the vault containing the tank floated and resettled, leaving the pipe columns tilted 0.95 degrees. Tank $8 \mathrm{D}-2$ is tilted 0.14 degrees off vertical. The actual tolerance for the angular orientation of the pipe columns is unknown. The actual tolerance for the center to center location of the pipe columns is also unknown.

2. Environment: The tank atmosphere is air at ambient temperatures between $45^{\circ}$ and $95^{\circ} \mathrm{F}$ and relative humidity up to $100 \%$. Vapors from the tank waste may at times be caustic or acidic. The tank waste chemistry is primarily liquid which may contain radioactive zeolite that will primarily range from $\mathrm{pH} 9$ to 12 . For short periods of time (during the last two months of the equipment service life) liquids may range from $\mathrm{pH} 4$ to 6 . However, the probability of this equipment experiencing the full $\mathrm{pH}$ range is low. 
3. Radiation: $500 \mathrm{R} / \mathrm{hr}$ peak of gamma radiation from predominantly cesium 137 sources. The system should remain operational after exposure to a total integrated dose of $1 \times 10^{7} \mathrm{R}$.

4. Geometry of the Risers: The minimum hole diameter in the tank roof is 25.62 inches. The minimum riser diameter is 26.94 inches. WVNS has plans to use a decontamination spray ring (not yet designed) near the bottom of the riser and this spray ring becomes the limiting diameter. The risers are not dented or ovaled and do not have protrusions into their interior. Riser M-1 of tank 8D-2 has a minimum diameter of 22.88 inches.

5. Tank Pipe Column Loads: No plastic deformation is permitted in the cross section of the 8 inch pipe columns. The maximum point load equals $1500 \mathrm{lbf}$; the maximum axial line load applied along a 2 inch line equals $2800 \mathrm{lbf}$.

6. Tank Damage: No damage is permitted to the tank walls and floor. No plastic deformation is permitted in the cross section of the 8 inch pipe columns. Localized surface contact marks are permitted, only on the 8 inch pipe columns. There are specified limits on column overall stress, column local stress and contact stress.

\section{Design Requirements}

1. Service Life: 2 years (4,500 hours minimum operating life).

2. Tank Damage: Provisions shall be incorporated in the equipment design to minimize stresses applied to the tank and prevent damage to the tank structure during normal operation and in the event of equipment failure.

3. Equipment Operation: The design shall incorporate provisions for failsafe operation. In the event of failure, equipment shall be remotely retrievable including controlled disengagement.

4. Equipment Movement and Use: The design of the system shall incorporate provisions for moving or handling equipment with a payload up to $100 \mathrm{lbm}$ at the end of the dexterous arm. A payload capacity of 200 $\mathrm{lbm}$ is desired but not required. Additionally, the design shall account for the reactive forces from tool use (such as: spray wand and brush/scraper) of $100 \mathrm{lbf}$ minimum. The system shall be able to move and position equipment to provide complete wash down capability of the tank floor, walls and internal structural members (up to $12 \mathrm{ft}$ off the tank floor for Tank 8D-1 and $22 \mathrm{ft}$ off the tank floor for Tank 8D-2). The system shall be able to position visual inspection or other equipment to view and inspect greater than $99 \%$ of the tank floor, walls, and internal structural members. 
5. Reliability: Provisions shall be incorporated to maximize reliability of all system components. Simplicity of the design shall be paramount. Proven off-the-shelf components and technology shall be used to the maximum extent practical.

6. Decontamination: Equipment shall function during and after immersion in waste liquids and be able to be decontaminated without damage from sprayed pressurized water $(10,000$ psi maximum) that may contain decontamination chemicals such as detergents and nitric acid.

7. Deployment: The system shall be capable of deployment through existing tank risers. Each riser has a nominal diameter of 25 inches, and the overall height from the tank floor to the top of each riser being approximately 47 feet.

8. Retrievability: In the event of equipment failure, all equipment shall be designed to be remotely retrieved.

9. Tether Management: All equipment shall incorporate tether management to prevent entanglement and tank damage. Tether replacement shall be incorporated as applicable. Provisions to permit disconnection of the tether between radiologically hot and cold areas shall be provided to allow use of the operator station with another tool delivery system.

10. Serviceability: All equipment shall be designed for ease of service. The use of a mobile crane is prohibited for normal operation and service (but is permissible for initial installation, retrieval, and re-installation into other risers).

11. Controls: All controls shall be designed to be user friendly and shall be standard replaceable components. The control system shall be designed to allow flexibility in the method of operation. The control station will be installed on-site within a WVDP-supplied weatherproof structure for operator comfort.

12. Interfaces: The system shall interface with the WVDP tank riser and pump support structure.

13. Design Verification: The system shall be fully tested and verified using a full-scale mockup of a portion of the tank. A prototypical unit(s) affixed to a mast shall be employed to verify in-tank operation and reliability. The system shall meet WVDP acceptance test requirements prior to delivery and deployment at WVDP.

14. Training: Formal training in operating, troubleshooting, and maintaining the system shall be provided to ensure proper use of all equipment. 


\section{Project Summary}

\section{System Description}

The Remote Tool Delivery (RTD) system overcomes many of the limitations of existing tank waste retrieval technologies. The RTD system converts the liability of extensive internal structures into an asset during tank waste retrieval. The tank internal structure is used as "scaffolding" to gain access to the tank interior, walls, ceiling, and floor. The RTD system is inserted into the tank by a Deployment Unit through a tank riser and rotated to its operating position. The RTD system can be operated from its deployment mast to perform tasks in the immediate area of the riser or, the RTD locomotor can "step off" the deployment mast and support itself on adjacent structures in the tank.

In such cases where greater mobility is needed, the RTD locomotor reaches out and secures itself to a nearby existing structural member inside the tank and then releases from the Deployment Unit mast. The RTD locomotor can then navigate around the tank by moving from structural member to structural member. The RTD locomotor can also translate vertically in the tank. The combined motion capabilities of The RTD locomotor allow it to reach all areas and elevations of a tank, provided sufficient structural members exist.

The RTD locomotor performs work by manipulating tools or equipment using a dexterous manipulator mounted on the locomotor. The RTD system can work alone or as a companion technology to a long-reach arm or floor-based system to perform waste retrieval.

The RTD system consists of three major components: the RTD locomotor, a Hydraulic Power Supply, and an Operator Control Station. 


\section{Locomotor}

\section{Locomotor}

The RTD locomotor is a three joint planar work platform that operates attached to a deployment mast or to the pipe columns in the tank (See Figure 1). The locomotor is comprised of seven major components: grippers, link, joints, vertical translation mechanism, locomotor hydraulic system, dexterous manipulator and video system. The components of the RTD locomotor are described in the following sections.

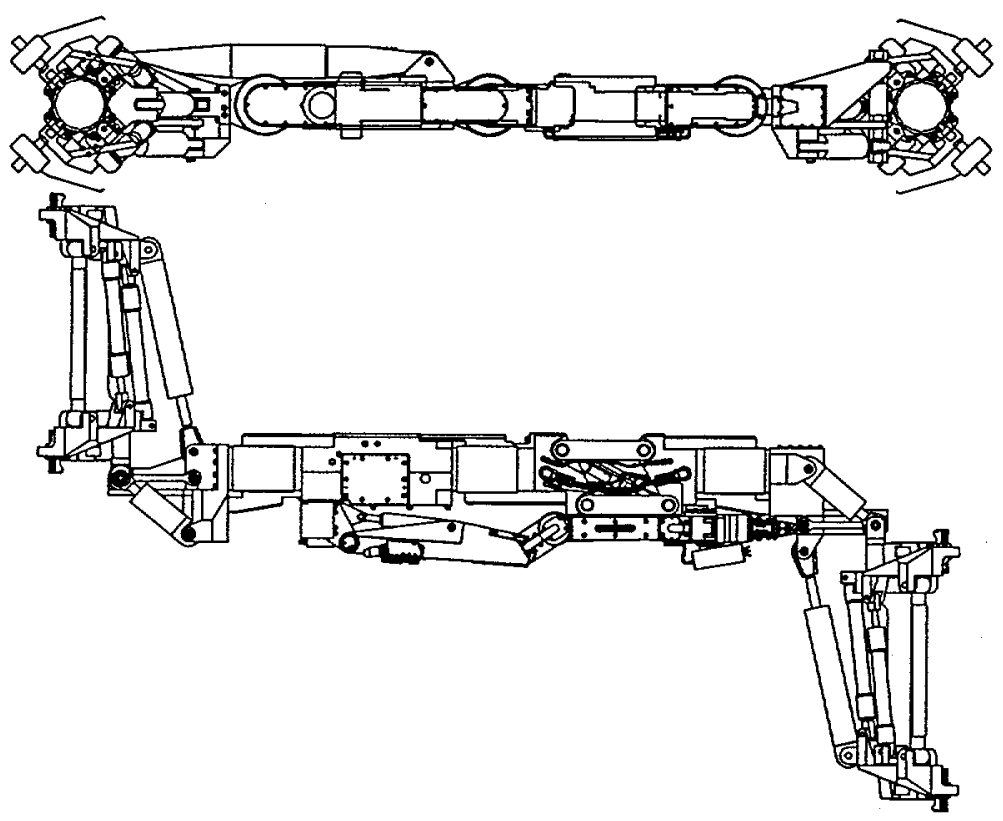

Figure 1 RTD Locomotor

Gripper Mechanism

The grippers on the RTD locomotor provide the following functions:

1. They secure the locomotor to the deployment mast during deployment and retrieval, or when the locomotor is used as a mast mounted manipulator to perform work tasks in the area of the deployment riser.

2. They secure the locomotor to the internal tank structure when the locomotor is used as a mobile platform for the dexterous manipulator.

A gripper mechanism is mounted to each end of the RTD locomotor. Each gripper mechanism consists of a gripper base and a gripper frame assembly which supports the 
pipe column gripping components. The gripper frame assembly is connected to the gripper base with a two degree of freedom actuated linkage (See Figure 2). The gripper base connects to the locomotor joint.

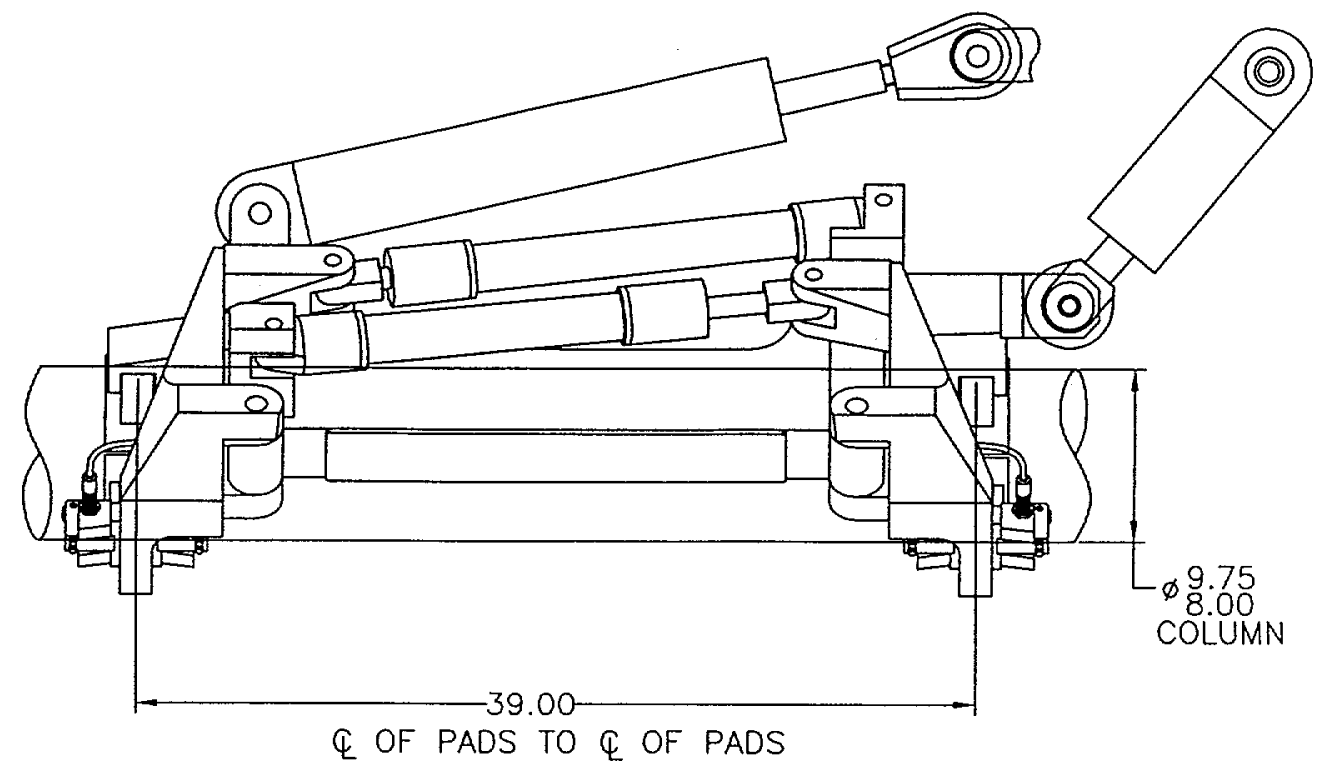

Figure 2 Gripper Assembly

Each gripper assembly has 16 gripper pads which make contact with the tank pipe column. The pads are mounted in pairs on pivoting links. The pads are free to pivot in the pivoting links. This double pivot allows best possible alignment of the gripper pads to the pipe column for load distribution. Four pairs of gripper pads are mounted to moving arms. The arms open to allow the gripper to be removed from a pipe column and provide adjustment to allow the gripper to close securely on different pipe diameters. Hydraulic cylinders are used to actuate the moving arms. Each moving arm has a hydraulic cylinder. The hydraulic cylinders for the moving arms contain an integral locking feature to secure the gripper to the pipe column in the event of a hydraulic system failure. A contact switch is located at each pair of gripper pads. The contact switches give a positive indication that the gripper is properly seated on the pipe column.

The gripper mechanism has three modes of operation: open, close, and lock. The open mode moves the gripper arms to release the gripper from a pipe column. The close mode moves the gripper arms to secure the gripper to a pipe column. The lock mode holds the gripper arms in a fixed position to prevent the gripper from releasing from a pipe column. The gripper defaults to the lock mode of operation should a failure occur. 


\section{RedZone}

The gripper mechanism is designed to minimize the contact stresses induced in the tank pipe columns while providing sufficient rigidity for locomotor and dexterous manipulator operations.

The grippers are fabricated from aluminum for weight reduction. Electroless nickel plating overcoated with epoxy paint is used for corrosion protection of the aluminum.

\section{Vertical Translation Mechanism}

A vertical translation mechanism is provided so that the height of the locomotor in the tank can be changed (See Figure 3). The vertical translation mechanism is an actuated four bar linkage. The linkage is operated by a hydraulic cylinder placed on the diagonal of the linkage. The cylinder produces $+/-6$ inches of vertical motion of the linkage. A linear potentiometer provides mechanism position information to the operator. The position sensor is needed so that the locomotor can be aligned for deployment and retrievial.

The vertical translation mechanism has four modes of operation: raise, lower, limp, and hold. The raise and lower modes are used to move the mechanism in the vertical direction, and the hold mode is used to maintain a fixed position. The fail-safe state of the vertical translation mechanism is the limp mode. In limp mode, the vertical translation mechanism descends under gravity to its lowest position.

The links and end connections for the vertical translation mechanism are made from aluminum.

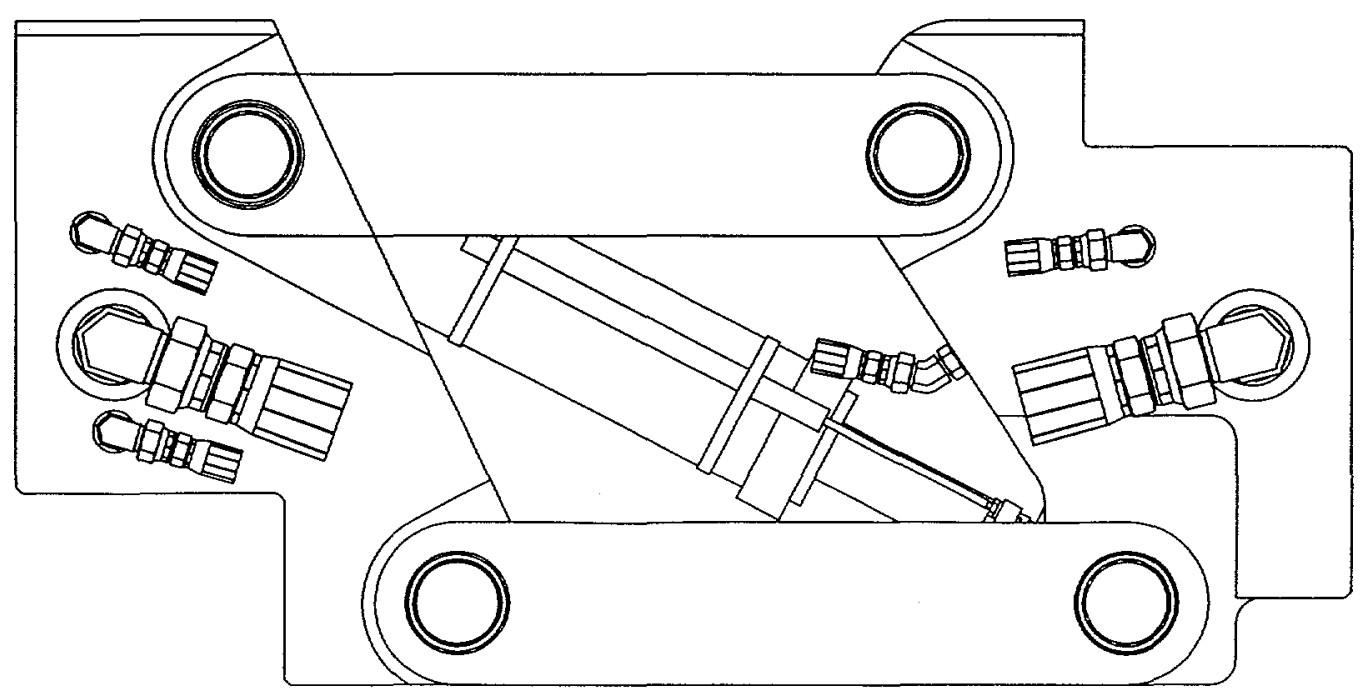

Figure 3 Vertical Translation Mechanism 


\section{RedZone}

Link

A link connects two of the locomotor joint rotary actuators on the RTD locomotor. The link provides a structural connection between the two actuators. It also provides an attachment point for the tether termination as well as distribution of hydraulic and electrical circuits. The dexterous manipulator is mounted on the link.

The interior of the link serves as an electrical cable and hydraulic hose passageway. All hoses and cables on the locomotor are internally routed where possible to prevent damage from contact with tank structure to improve system reliability.

The link is fabricated from aluminum for weight reduction. Electroless nickel plating overcoated with epoxy paint is used for corrosion protection of the aluminum.

The link is designed to minimize the decontamination time for the locomotor. The exterior surfaces of the link are smooth to prevent contamination buildup, and the internal chamber of the link is sealed to prevent internal contamination. 
Joints

Three locomotor joint assemblies are used in the RTD locomotor. Each locomotor joint is a modular assembly containing a hydraulic rotary vane actuator with integral bearings, a hydraulic rotary union, and a position sensor. (See Figure 4) The joint has low friction to enable a limp fail-safe condition. The integral rotary union passes hydraulic fluid between locomotor links. A through-hole in the rotary union allows electrical cables to pass through the rotary joint. Each joint contains a resolver for position sensing. The resolver provides absolute position feedback. Resolvers are used for their resistance to interference and degradation by ionizing radiation. Actuator specifications are given in Table 2.

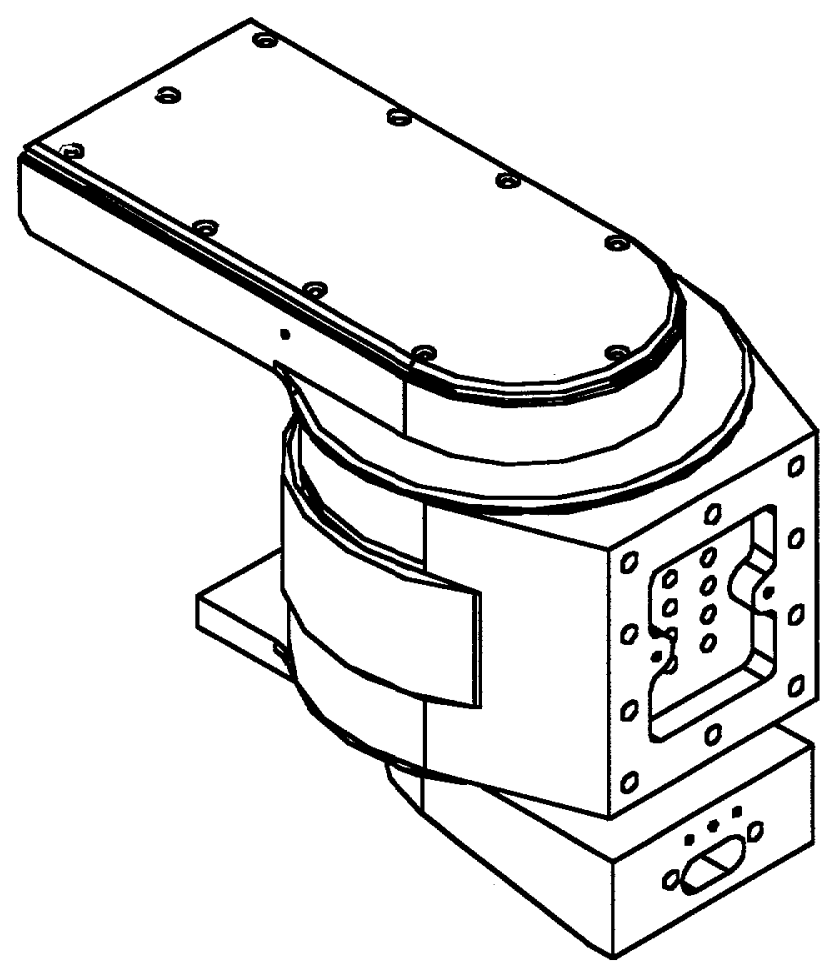

Figure 4 Locomotor Joint 


\begin{tabular}{|l|l|}
\hline Actuator Style & Single Vane Type, Double Shaft Configuration \\
\hline Hydraulic Fluid & Shell Tellus 32 mineral oil \\
\hline Ambient Temperature & $0^{\circ} \mathrm{F}$ to $100^{\circ} \mathrm{F}$ \\
\hline Environment & Caustic, $\mathrm{pH} 9-12$, may be $\mathrm{pH} 4-6$ for short period \\
\hline Actuator/Swivel Friction & $250 \mathrm{ft}-\mathrm{bf}$ maximum \\
\hline Cross Vane Leakage & $0.1 \mathrm{gpm}$ maximum at suggested operating pressure \\
\hline Swivel Leakage Rate & $\begin{array}{l}0.01 \text { gpm to Tank line at } 3000 \mathrm{psi} \\
\text { No leakage between other passages or to external }\end{array}$ \\
\hline Radiation & $\begin{array}{l}\text { Peak Dose Rate of } 500 \mathrm{rad} / \mathrm{hr} \\
\text { Total Cumulative Dose of } 10^{7} \mathrm{rad}\end{array}$ \\
\hline Rotation Travel & 230 deg minimum \\
\hline Rotational Speed & 10 deg/sec maximum \\
\hline $\begin{array}{l}\text { Net Output Torque Under Full } \\
\text { Load }\end{array}$ & 21,631 in-lbf minimum \\
\hline Operating Pressure & $3,000 \mathrm{psi}$ \\
\hline Moment Load & $150,000 \mathrm{in}-\mathrm{lbf}$ \\
\hline Axial Load & $2138 \mathrm{lbf}$ \\
\hline
\end{tabular}

Table 2 Locomotor Joint Specifications

The locomotor joints are fabricated from 4130 steel with a corrosion protective finish.

\section{Locomotor Hydraulic System}

The locomotor hydraulic system, in conjunction with control electronics, provides controlled motion of the locomotor joints, grippers and vertical translation mechanism. Hydraulic fluid is supplied to the locomotor by pressure and return hoses in the tether. Hydraulic fluid is also supplied to the dexterous manipulator.

The locomotor hydraulic system uses radiation hardened servo valves and directional control valves to operate the hydraulic actuators. The servo valve electronics are located outside the tank environment to protect them from radiation exposure. Hydraulic manifolds in the locomotor provide hydraulic power distribution throughout the locomotor and mounting locations for the servo and directional control valves.

Additional valves are needed to meet fail-safe requirements, i.e., fail-safe limp of the locomotor joints and vertical translation mechanism. These valves are also incorporated in the manifolds.

A multi-passage hydraulic rotary joint is incorporated into the locomotor joint rotary actuator to pass fluids through the locomotor. This provides a more compact design and eliminates the use of hoses in this high flex area. 


\section{RedZone}

Stainless steel tubing and manifold passages are used where possible to minimize the use of flexible hoses to improve reliability. Figure 5 (attached to the end of this report) shows the hydraulic schematic of the locomotor.

\section{Video System}

Five black and white camera and light assemblies are used on the locomotor. Two cameras are mounted on each gripper to assist the operator in positioning the gripper on the pipe column. One camera is mounted on the dexterous manipulator to provide a view of the manipulator work area. This camera can also be used to provide some overview capability.

All of the cameras are based on the Rees R980 camera with a Chalnicon image tube. This camera will operate at a dose rate of $10^{5} \mathrm{rad} / \mathrm{hr}$ and survive a total dose of $10^{8} \mathrm{rad}$. This comfortably exceeds the dose rate and total dose expected for the RTD system. Customized housings are used for all cameras. The cameras and lights are sealed for underwater use. Mounting of the lights is designed to minimize heat transfer to the cameras.

Lens cleaning is provided by a water/air spray nozzle at the camera. Lens cleaning is initiated from the Operator Control Station. A separate lens cleaning control is provided for each camera. A spray of water from the nozzle dislodge waste material from the camera lens. A subsequent air blast removes water droplets. This lens cleaning system has been demonstrated on the Houdini ${ }^{\mathrm{TM}}$ system at ORNL and is very effective.

\section{Dexterous Manipulator}

The locomotor is equipped with a dexterous manipulator to perform work in the tank. The dexterous manipulator is mounted to the locomotor link. The locomotor is used as a mobile base for the dexterous manipulator. The dexterous manipulator is controlled from the Operator Control Station.

A Schilling Titan III manipulator is used. Specifications for the Titan III manipulator are listed in Table 3. The payload capacity of the Titan III manipulator is limited to $100 \mathrm{lbf}$ by a pressure regulating valve in the locomotor. 


\begin{tabular}{|l|l|}
\hline Payload & $100 \mathrm{lbf}$ at full reach at $3000 \mathrm{psi}$ \\
\hline Reach & $75.4 \mathrm{inches}$ \\
\hline Wrist Torque & $60 \mathrm{ft}-\mathrm{lbf}$ \\
\hline Jaw Closure Force & $1000 \mathrm{lbf}$ \\
\hline Weight & $221 \mathrm{lbf}$ \\
\hline Operating Pressure & $3000 \mathrm{psi}$ maximum \\
\hline Hydraulic Fluid & Shell Tellus 32 or equivalent \\
\hline
\end{tabular}

Table 3 Titan III Manipulator Specifications

\section{Locomotor Control Strategy}

Two locomotor control methods are provided for the operator to move the locomotor in the tank. The control method will be selected with a switch on the control console. The control methods are described below.

\section{Joint Control}

The simplest method for controlling the motion of the locomotor is independent control of each joint. A rocker switch is provided for each locomotor joint. Each joint is servo controlled and will follow the control input. Joint speed will be limited to prevent unwanted locomotor dynamics.

\section{Coordinated Joint Motion}

With this control method, the rotation of all three joints will be coordinated by the control system to achieve the operator specified movement of the free locomotor gripper. A three degree of freedom joystick will be used to control the position and orientation of the free gripper of the locomotor. The control system will determine the required motion of the actuators to achieve the desired gripper position and orientation. Joint speed will be limited to prevent unwanted locomotor dynamics.

\section{HPU}

The Hydraulic Power Unit (HPU) for the RTD system is an independent system connected to the locomotor tether with a 125 foot long heated hydraulic hose bundle. It is housed in an environmental enclosure with access doors for maintenance. The environmental enclosure contains a skid mounted motor, pump and 60 gallon reservoir, plus two electrical enclosures (power switchgear and signals). External $480 \mathrm{VAC}$ power, switchgear control lines and feedback are connected to the enclosure. The HPU can be mounted up to 250 feet from the control console.

The motor and pump can continually supply 10 GPM of hydraulic fluid at 3,000 psi. A separate cooling and filtration "kidney" loop provides continuous filtration and cooling 
for $100 \%$ of system capacity up to $100^{\circ} \mathrm{F}$ ambient temperature. The reservoir is heated to maintain the reservoir fluid at $40^{\circ} \mathrm{F}$ minimum at $-10^{\circ} \mathrm{F}$ ambient. The system has an accumulator and relief valve. The system operates with Shell Tellus 32 hydraulic fluid.

The HPU switchgear enclosure contains the control devices to manage power to the HPU. The main power circuit breaker is manually operated, and can be tripped by a ground fault. Motor starters with overcurrent and thermal protection control the hydraulic pump, the kidney pump, cooling fan and reservoir heater. Software control prevents the motors from starting simultaneously, to avoid excessive inrush currents. All motor starters can be disabled by a redundant, series connected, hardwired Emergency Stop chain. A break in the electrical chain wiring will also trigger an E-Stop shutdown.

The HPU signal enclosure contains the connection points for feedback signals from the HPU and locomotor to the control console. The sensor signals in the HPU include reservoir temperature, reservoir level, hydraulic supply pressure and two hydraulic filter clog switches.

The environmental enclosure also contains a pressurized water/air system to clean the locomotor camera lenses via the tether. Water is pumped down the 250 psi line in the tether. This washes the camera lenses. Air follows down the same line to dry the water droplets from the camera lenses. The capacity of this system is 2 GPM of water at $60 \mathrm{psi}$ and 10 SCFM of air at 250 psi.

\section{Control Station}

The Operator Control Station is to be located in a WVNS supplied control trailer. The Control Station consists of the Control Console and the Control Rack. The operator controls the system from the Control Console. The Control Rack is a 19" rack mount enclosure that includes the following equipment: A VME subrack provides the actuator control CPU, I/O modules to interface to the analog and digital signals from the locomotor and HPU, and hardware interlocks to prevent illegal motion commands to the locomotor. A camera control unit, video router and quad splitter allow the operator to select appropriate camera views. Power distribution provides power to the rack equipment, the hydraulic solenoid valves throughout the system, the camera lighting, servo amplifiers and $120 \mathrm{VAC}$ auxiliary loads.

The Control Console consists of two separate working surfaces, the Control Panel and the Status Panel. The Control Panel contains controls used more frequently to operate the locomotor. The Status Panel contains controls used less frequently, as well as status indicators. Three black and white video monitors provide feedback from the locomotor and overview cameras. Any camera can be displayed on any monitor and one of the monitors can display four views simultaneously using a quad splitter. The operator can choose anywhere between one camera displayed on all three monitors, and six separate views. A touchscreen display provides additional control input and status information, camera mappings, plus interlocking menus and procedures. 


\section{RedZone}

R o b o t i c s

The Control Panel contains switches, indicators, joysticks and the dexterous manipulator master arm. These controls allow the operator to do the following:

- Raise and lower the vertical translation mechanism.

- Select either coordinated joint control or individual joint motion, and select which joint is being controlled by the joystick in individual joint mode.

- Move the three rotary actuators using a joystick. Switches on this joystick provide deadman safety and tether payout functions.

- Select which gripper is to be controlled.

- Move the tilt and rotate functions on the selected gripper using another joystick. Switches on this joystick provide the deadman and gripper open/close functions. Hardware interlocks guarantee that one gripper will not release unless the other gripper is firmly attached to a column. Software interlocks are automatically checked before locomotor or gripper motion.

The Control Panel contains indicators for locomotor motion mode, rotary actuator selected, vertical translation mechanism position, gripper selected, and gripper contact switches to make sure each gripper is holding. The dexterous manipulator master control arm is mounted on an elevated bracket that inverts the master arm. Since the slave arm is mounted inverted to the underside of the locomotor, this provides intuitive master arm kinematic control for the operator.

The Status Panel contains the controls and indicators for the HPU, the dexterous manipulator master controller unit, and the locomotor cameras. Controls are included to turn the HPU on and off, turn the spray wand for cleaning the tank on and off, control all locomotor camera functions except lights, the Emergency Stop function, and to silence the audible alarm when a fault condition occurs. This panel contains indicators for system power, HPU status, hydraulic functions and the spray wand operational status. The locomotor camera lights are controlled by the touchscreen. 


\section{Results and Discussion}

\section{Current Status}

Due to several factors related to West Valley operations it was concluded that the delivery schedule for the final Tarzan system was not compatible with West Valley's needs. In addition, West Valley has been experiencing better recovery than expected using the sluicing method currently in practice. Based on these factors, a decision was made to stop the Tarzan assembly until a modified statement of work could be developed. Based on lengthy discussions with FETC and West Valley, RedZone submitted a change in scope to bring the assembly work to a logical conclusion point. In addition, we are collating all existing documentation for final delivery. As manufacture of some parts of the system is not complete, the final package does not represent the design in all aspects. In particular, the actuator did not pass the preliminary testing after several attempts. The changes to the final actuator design have been conceived, but due to the cost and time required, we will not be manufacturing a final actuator to prove the design.

The system has been assembled to the extent possible to reduce the total number of discrete parts which must be stored. With respect to each major subsystem, this means the following:

Locomotor - With the exception of the three rotary actuators, all of the locomotor purchased and fabricated parts were received. The appropriate parts were nickel plated. The parts were assembled into the major subsystems, namely the two grippers, the two wrists, the link, and the vertical translator. The subsystems were assembled together to the extent possible without the three rotary actuators. No hydraulic plumbing or electrical wiring was done on the locomotor subassemblies.

Dexterous Manipulator - The Schilling dexterous manipulator was received from the manufacturer and tested. It was shipped separately, at West Valley's request. The Schilling Master Controller was installed in the control console, but was removed and shipped with the manipulator.

Cameras - The two dual gripper cameras and the manipulator wrist camera were received from the manufacturer. The cameras were tested by the manufacturer and demonstrated at RedZone. The cameras have not been installed on the locomotor subassemblies.

Tether Reel - The tether reel was received from the manufacturer and inspected. No further assembly was done on the tether reel since integration had not progressed that far when the project scope was modified. 
HPU - The Hydraulic Power Unit was received complete from the manufacturer and installed in its environmental enclosure. The HPU was tested by the manufacturer prior to shipment. This item is complete except for a minor red tag item (an extra sight glass was installed by the manufacturer).

Control Console - The control console furniture, panels and panel components were received and assembled. The Schilling manipulator Master Controller was installed into the control panel. The camera controls were also installed. The control panel was wired. The Control Rack was assembled and wired, including power supplies, electronics chassis with computer, memory and I/O cards and video equipment. The Schilling Master Controller was removed so that it could be shipped with the Schilling arm. The control console is complete with the exception of the Schilling Master Controller.

Bulkhead Panel - The bulkhead panel was fabricated and the connectors, fittings, power supplies and other electronics were assembled on to it. This item was completed to the level of integration accomplished at the time the project scope was modified.

Interconnect Cables - The interconnect cables were received from the manufacturer, inspected, and sent back to the manufacturer for some rework. The reworked cables were received and inspected. They are complete, but have not been integrated into the system.

There are additional smaller parts that have not been installed because the integration had not proceeded to that point at the time the contract was modified. The final disposition of all the parts is still open, but in the event that the system is required at some point downstream, the design will be available and the project could be revived. Based on this current status, it is difficult to discuss any concrete results since the final system is not operational. The following chapter does discuss some of the lessons learned through the development effort. 


\section{Conclusions}

\section{Lessons Learned}

Through the course of the Tarzan development RedZone worked closely with the technical experts at West Valley to determine the needs and requirements for the system. The technical communication was very good, but sometimes RedZone's and WVNS's QA and documentation requirements were not in unison. The following section details some observations and conclusions related to the Tarzan development.

The design of a rotary actuator to meet the requirements of the Tarzan system turned out to be more challenging than we had expected. Unfortunately, the initial vendor selection was deemed inadequate upon evaluation of their initial prototype. This added significant time and cost to the project. Subsequently, we did proceed with a vendor capable of building an actuator to meet our specifications, but several iterations were required to generate a final design. Thus the actuator design trailed the rest of the project creating a significant technical risk to program success.

In addition, we experienced significant difficulty in implementing West Valley's QA and documentation requirements. Through the various stages of the project, WVNS identified several areas where West Valley expectations for the level of documentation were not being met by RedZone's standard practice. Initially, RedZone was not cognizant as to the extent of documentation (such as Certificates of Conformance, Certified Material Testing Reports, and Instrument Calibration Certificates) that was required from vendors. Later, verification that the required documentation was shipped with the parts was not done on a consistent basis. In several cases this forced RedZone to travel back to recapture documentation not initially requested or received. This added significant effort that could have been avoided had we understood the requirements up front. In the end, West Valley provided an on-site liaison to assist us in preparing the documentation requirements to meet West Valley's needs. This proved to be a good solution to preventing any mismatch in expectations. Eventually, detailed procurement specifications were written for major subsystems that defined the critical requirements for the subsystem and requested documentation that the requirements were met. These subsystems included the HPU, Rotary Actuator, Tether Reel, Slip Ring, Gripper Cylinder, Gripper Camera, Tether Assembly, VTM Feedback Device, Interconnect Cabling, Gripper Pads, Nickel Plating and Painting.

Finally, RedZone was not fully sensitive to the importance of maintaining timely schedule and budget information. As the project moved forward RedZone brought on new staff members who were not as experienced in driving the project to key milestones and management oversight did not identify the difficulties in a timely fashion. As a result, the project schedule and budget were affected adversely. We have worked to correct those problems and have now adopted a different structure which 


\section{RedZone}

allows us to track schedule and budget on all of our projects in a more effective manner. The following items are part of this new structure. A schedule was developed based on a finely detailed Work Breakdown Structure, and a budget was tied to that schedule. The budget and schedule were monitored weekly, and variance reports were issued. The schedule was reviewed at the weekly conference calls and off schedule items were identified and discussed for faster resolution. New procedures were implemented in house dealing with the inspection and receipt of items to assure that requested documentation was included with the item. Inspection and documentation for purchased items was emphasized in recurrent QA training for all employees. 


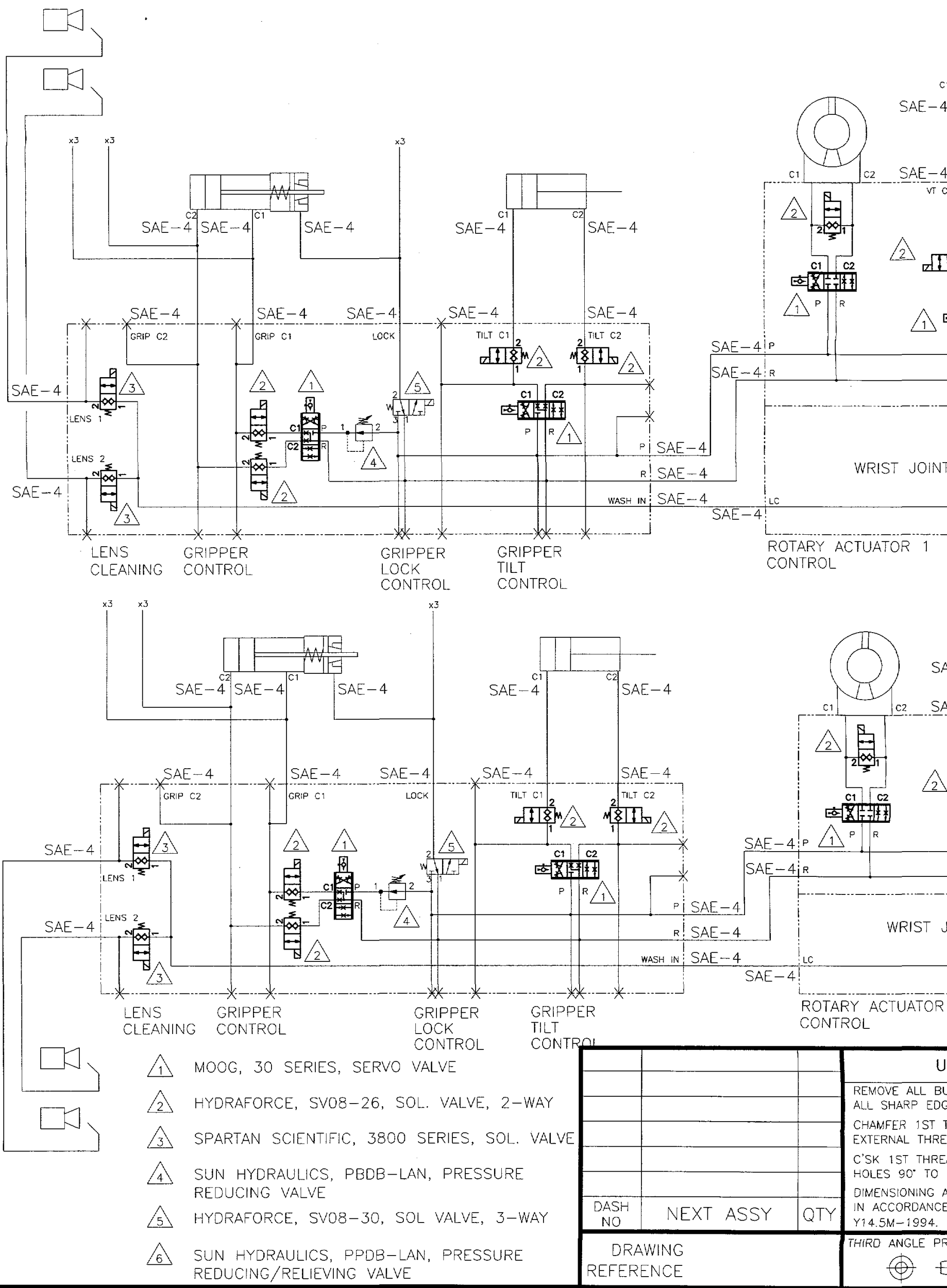


